\title{
Relationship Between Fear of Missing Out (FoMO) and Problematic Smartphone Use (PSU) in Generation Z with Stress as a Moderator
}

\author{
Kevin Adrian ${ }^{1 *}$ Riana Sahrani ${ }^{1}$ \\ ${ }^{I}$ Faculty of Psychology, Universitas Tarumanagara, West Jakarta, Indonesia \\ *Corresponding author, Email: rianas@fpsi.untar.ac.id

\begin{abstract}
Recently, Generation Z is said to be the successor of the Millennial Generation. Generation $\mathrm{Z}$ is known as the versatile generation through all advanced technologies such as smartphones. The American Psychological Association survey in 2018 found that Generation $\mathrm{Z}$ is one of the most stressful generations. There are 55\% of them doing coping stress using social media. Currently, the use of social media can be done via a smartphone. However, in recent years the use of smartphones has created new problems, namely fear of missing out (FoMO) and problematic smartphone use (PSU) and was found to have a positive relationship between FoMO and PSU. Until now, there has been no further research that explains the role of stress in the FoMO and PSU relationships, especially for Generation Z. So the aim of this study is to see the role of stress moderators on the relationship between FoMO and PSU in Generation Z. The study was conducted on 300 people with a range of age 13-23 years who were conducted from November to December in 2020. The results obtained were that FoMO had a positive and significant relationship with PSU, but stress was found to have no role moderator on the relationship between FoMO and PSU. So, it can be concluded that stress cannot be a moderating variable on the relationship between FoMO and PSU.
\end{abstract}

\section{Keywords: Fear of Missing Out (FoMO), Problematic Smartphone Use (PSU), stress, generation z}

\section{INTRODUCTION}

The development of information technology in a decade has progressed very rapidly, especially in the area of internet access such as the development of smartphone devices and supporting applications such as social media using internet access. The internet itself was introduced in the 1980s and became commonly used in the mid-1990s [1]. The arrival of the smartphone in early 2010 , which was introduced by Apple at that time, became a breakthrough for a new era in human civilization because only through cell phones, we can use the internet wherever and whenever we want. This is evidenced by the latest data on smartphone users in the world that has reached 3.5 billion users in 2020 [2]. Adolescence cannot be separated from this phenomenon. In fact, $95 \%$ of teenagers in America say they have a smartphone and $45 \%$ of them admit to using it very often and cannot be separated from a smartphone [3]. In the same survey, it was found that $85 \%$ of teenagers have used YouTube, $72 \%$ of teens have an Instagram account, $69 \%$ use Snapchat, 51\% use Facebook, and 32\% for Twitter. From the above applications, $32 \%$ of teenagers admit that they open Youtube too often, 35\% cannot escape Snapchat, and $15 \%$ use Instagram very intensely. Of these, only $3 \%$ of teenagers in the United States admit to not having an account or using the above social media.
Another survey also explained that the average time for Indonesians to use smartphones has reached 4 hours and has passed the global average smartphone usage of 3 hours 40 minutes [4], [5]. Another surprising thing is found in the APJII survey [6] which found the age group 15-19 years used the most internet at $91 \%$, followed by the $20-24$ age range at $88.5 \%$ and $25-29$ at $82.7 \%$ in Indonesia. Based on the American Psychological Association (APA) [7] has classified Generation Z into births from 1997 to 2003, which means that in 2020 their age is $17-23$ years, so it can be ascertained that Generation $\mathrm{Z}$ is the generation that uses the internet and smartphones the most.

The beginning of depression is stress, and stress can cause depression [8]. Stress is a condition of a person's inability to face a stressor in life [9]. Stressors are things that cause stress on a person. In a recent survey conducted by APA [7], it was found that Generation $\mathrm{Z}$ is the generation with the highest average stress, namely 5.3 with Millennial Generation in first place with a score of 5.7 and Generation $\mathrm{X}$ in third place with a score of 5,1 (where 1 is low stress level, and 10 is very stressful). Even so, APA notes that Generation $\mathrm{Z}$ is the generation with the lowest mental health level with a score of only $45 \%$ when compared to Millennial Generation with a score of $56 \%$ and Generation X 51\%. The survey also found that $55 \%$ of Generation $\mathrm{Z}$ did stress 
coping through social media, and $45 \%$ felt less suitable for coping with stress using social media.

As if it is in line with the previous APA survey, Anderson and Jiang [3] explain that teenagers who are Generation $\mathrm{Z}$ currently tend to seek coping stress using social media by contacting their relationships. This is also agreed by Kardefelt-Winther [10] in his theory, namely the compensatory internet use theory which explains that when someone experiences problems or life pressures (it can be seen as stress), using the internet is one way to escape or can be coping stress for they.

In fact, the internet and smartphones were created to help human activities such as studying, working, shopping, distributing information quickly, or connecting with one another easily. Even so, it is like a double-edged sword, in recent years there has been a new phenomenon that is being studied and can be said to be a negative impact of the development of information technology itself, namely problematic smartphone use (PSU). PSU is a state of a person's inability to refrain from using a smartphone excessively which can interfere with a person's daily life [11]. In a study conducted by Lee and Lee [12] in South Korea, it was found that school adolescents (Junior High School and Senior High School) are very vulnerable to experiencing PSU. In line with previous studies, Arthy et al. [13] found that the PSU phenomenon occurred mostly in adolescents aged 12-15 years. In addition to school adolescents, at the age of late adolescence who study at university are also vulnerable to experiencing PSU and can even interfere with the quality of learning at universities [14]. These ages are the age of Generation Z. Research in recent years, PSU is often associated with fear of missing out (FoMO), which is a new construct as well, and develops along with technological developments in the past two decades [15].

FoMO is an excessive anxiety for someone who feels that he always wants to be the first to find out some information, always doesn't want to be left behind from others, always wants to connect with others all the time, and usually does not have positive benefits for his actions [15], [16]. FoMO mostly occurs at a young age such as adolescence, especially in boys [15]. This age is a natural thing because they tend to seek a lot of friendships and relationships with each other, especially made easier by the internet, smartphones, social media platforms to online games, so that at that age there is a risk of FoMO [17], [18]. This can occur because there are uncomfortable feelings or emotions if they feel disconnected or left behind on social media such as Facebook, Instagram and so on [19], [20].

Within nearly a decade, FoMO and PSU have been intensively researched along with the development of information technology. Recent studies have found that there is a positive, two-way relationship between FoMO and PSU both cross-sectional and longitudinal [21], [22]. This is also clarified by Elhai, Gallinari, et al. [23] and Moore and Craciun [20] that FoMO is closely related to smartphone use addiction. Low self-control combined with high levels of FoMO were also found to play a role in excessive smartphone use (PSU) because they were unable to withstand the feeling of FoMO in themselves [24]. In addition to adolescence, previous research has also shown that FoMO and PSU also occur at college age or early adulthood [15], [17], which means that FoMO and PSU occur mostly at the age of Generation $\mathrm{Z}$.

Initially, FoMO was found to be unable to mediate between depression and PSU [25]. However, in subsequent studies that have quite different results, FoMO was found to be insignificant as a mediating variable between depression and PSU, only in terms of information sharing or online discussion forums on social media, but rather to get or find the latest information contained in social media such as the latest or trending news [23]. Then if PSU and depression are bivariate linked, they do not have a significant relationship [26], [27]. As if to refute the previous statement, Elhai, et al. [28] through systematic review research clearly explains that depression has a significant relationship with smartphone addiction (PSU). A person who is experiencing stress is likely to seek entertainment through his smartphone until it lasts late at night, instead of getting entertainment, his stress level may increase [29], [30].

Based on the description of the phenomenon, survey data and previous research, then the fact that until now, there has been no further research that makes stress a moderator between the two new constructs or linking it to Generation $\mathrm{Z}$ is the reason the authors are interested in researching it. It has also been explained previously that depression and stress have a relationship between FoMO and PSU both bivariate and multivariate and many occur in adolescents to early adulthood or it can be called Generation Z. This research is very important to do in order to get the latest knowledge about the description and description of phenomena from the variables FoMO, PSU and stress in Generation Z.

\section{BACKGROUND}

\subsection{Fear of Missing Out (FoMO)}

Fear of Missing Out (FoMO) is a construct that is still very new in the world of knowledge [31]. FoMO occurs and develops along with the development of information technology. FoMO is a person's fear or fear of wanting to feel always connected to other people or something he likes, or anxiety that other people are more up-to-date than himself, which actually does not have any benefit behind this [15], [16], [32]. FoMO occurs mostly in adolescence and early adulthood and mostly occurs in men [17], [32]. FoMO is always identified with the use of social media and the internet, although it may occur outside the context of internet use [33].

\subsection{Problematic Smartphone Use (PSU)}

Problematic Smartphone Use (PSU) is a new problem that has emerged in this digitalization era, especially after the development of smartphones was created in 2007 by the late Steve Jobs. PSU is excessive use of smartphone devices and 
can interfere with a person's daily activities [11]. PSU is a synonym for smartphone addiction [34]. Gutiérrez et al. [35] explained that the behaviors and symptoms experienced by PSU are identical to those of someone who is addicted to the use of illegal drugs, such as excessive use or exceeds normal limits, being unable to hold back, tolerate or cannot escape from a smartphone to stay calm, and so on. When an individual feels addicted, he will not be able to get off the smartphone otherwise he will experience negative feelings [28].

\subsection{Stress}

Stress is a self-response to pressure that comes from externals or our environment that can disturb one's internal or self-calm [9], [36]. Stress spurs us to always adapt or adapt to the environment, pressures, and the problems we will continue to face throughout life [36]. Things that cause stress are called stressors [36]. Stressors can be in the form of relationship problems with others, with duties and responsibilities, or even things that we consider trivial for example the noise of surrounding vehicles [36].

Lazarus [37] argues that in fact stress leads to the value of the subjectivity of a person's values rather than objectivity. Stress can be assessed as a threat or danger, but there are also individuals who perceive stress as a challenge [37]. Even so, Cohen et al. [38] stated that stress can be measured objectively, by creating a measuring instrument for perceived stress scale (PSS) which will also be used in this study.

\section{METHODS}

The participants obtained by the author were as many as 300 people with an age range between 13-23 years with reference to a survey conducted by APA [7], namely the maximum age of Generation $\mathrm{Z}$ is 23 years (born in 1997), and a minimum age of 13 years to have accounts from various social media. such as Youtube, Facebook, Instagram, Twitter, Pinterest to the popular application, TikTok [39]. Because the meaning of the birth year of Generation Z has quite a lot of differences [7], [40]-[43], the authors agree to use the maximum age limit of APA (2018) and the minimum age limit for social media users [39]. Then own a smartphone and any social media accounts and use it at least 4 hours or more per day. The time of 4 hours is obtained based on the latest data that the average smartphone usage globally is 3 hours 40 minutes [4], so if it is more than that, it can be concluded that the usage has exceeded the limit or is excessive.

For the FoMO measurement tool, the Fear of Missing Out scale (FoMOs) was used by Przybylski et al. [15] which has been adapted into Indonesian by Sutanto [44] with a value of $\alpha=0.830$ out of the 300 participants obtained. For PSU using the Smartphone Addiction Scale Short Version (SASSV) developed by Kwon et al. [45] as a more compact version of the first measuring instrument and has been translated by Arthy et al. [13] became Indonesian with a value of $\alpha=0.818$ from 300 participants. For stress using the Perceived Stress Scale-10 (PSS-10) in Indonesian which was translated by Lim and Kartasasmita [46] developed by Cohen et al. [47] and has undergone an adjustment from 14 items to 10 items with a value of $\alpha=0.785$ of the 300 participants who participated in this study.

\section{FINDINGS AND DISCUSSIONS}

Table 1 Correlation test between fear of missing out and problematic smartphone use

\begin{tabular}{llll}
\hline & & Problematic Smartphone Use & Explanation \\
\hline Fear of Missing Out & $\mathrm{r}$ & 0.467 & Positive relationship \\
& $\mathrm{P}$ & 0.000 & Significant \\
\hline
\end{tabular}

Before conducting the regression test, the authors first conducted a correlation test to see whether FoMO as IV had a relationship with PSU as DV. It is also necessary to find out whether these two relationships are allowed or not to do a regression test, if there is no relationship then these two variables cannot perform a regression test with the stress variable as the moderator variable. Correlation testing is done using the Pearson correlation. The results obtained by the author on testing the Pearson correlation were $\mathrm{r}(300)=$ $0.467, \mathrm{P}<0.05$. Through these results, the authors conclude that the relationship between FoMO and PSU has a positive and significant relationship. It can be interpreted that when the FoMO variable is high, the PSU variable will also be high, conversely, if the FoMO variable is low, the PSU variable will also be low. To see the details of calculations and data, see Table 1.

The relationship between FoMO and PSU, it was found that there was a significant positive relationship. The results of this study are in line with previous research which explains that there is a positive two-way relationship between the two variables [21]. So it can be said that if someone has a high enough FoMO level, then that individual also has a fairly high PSU level. Likewise, if someone has a low FoMO level, then the PSU level is also low. Previous research has also found that the relationship between FoMO and PSU cannot be separated [20]. This can happen because someone who experiences FoMO always feels like connecting with others, then uses social media to easily stay connected to each other via a smartphone [23]. 
Table 2 Simple regression analysis between fear of missing out and problematic smartphone use

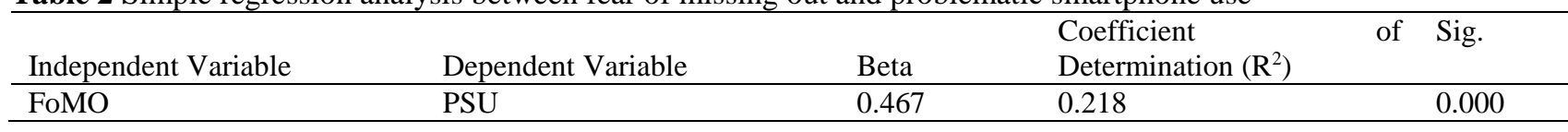

After it was found that the variables IV (FoMO) and DV (PSU) had a positive and significant relationship, the next step was to conduct a simple regression test to see how big the role of FoMO on PSU as IV. This step is very important to take in order to see how big the role of the moderator variable, namely stress, on the moderated regression analysis (MRA) after this step. In the simple regression analysis, the authors get data that FoMO has a role of $21.8 \%$ of the PSU as a variable IV, with the role of other variables not examined in this study amounting to $78.2 \%$. The value of $\beta=0.467, \mathrm{P}<0.05$, which means that FoMO has a significant relationship with PSU. For clearer calculation details, the authors provide Table 2 .

Table 3 Moderated regression analysis of variable fear of missing out, stress, and problematic smartphone use

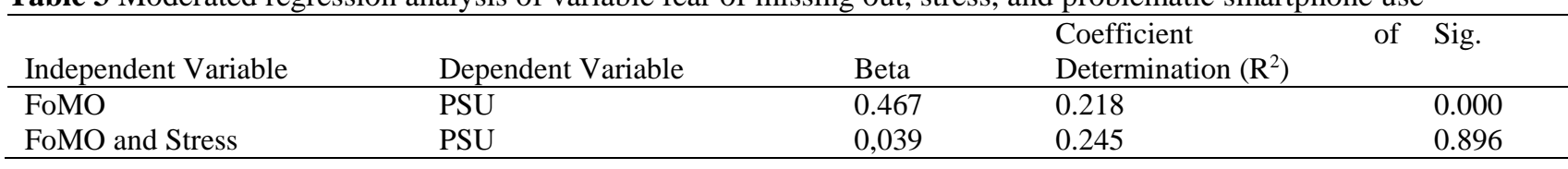

The final step is to perform MRA test between FoMO as IV, stress as moderator variable, and PSU as DV. The purpose of this test is to see whether stress as a moderating variable is able to increase or even decrease the role and / or relationship between FoMO and PSU.

The results obtained from the MRA test are as follows in table 3. In the previous simple regression test between FoMO and PSU, it was found that the role of FoMO on PSU was $21.8 \%$. With the presence of stress as a moderator for these two variables (IV and DV), it was found that there was an increase of only $2.7 \%$ and the significance value exceeded 0.05 , namely 0.896 . It can be interpreted that stress cannot be a moderating variable. This breaks the assumption of compensatory internet use which states that when someone experiences stress in the real world, people will tend to look for outlet using the internet [10]. There are three reasons why this theory can be refuted. First, in a systematic review research conducted by Elhai et al. [28], found that PSU and stress have only a mild relationship, inversely proportional if the PSU is juxtaposed with depression sufferers. Second, Przybylski et al. [15] explained that FoMO is actually a variable that is more likely to lead to anxiety than a variable related to depression (depression related variable). This is also confirmed in research conducted by Elhai, Yang, Fang, et al. [25], who found that anxiety or anxiety was more associated with FoMO than depression or depression-related variables such as stress. Third, the last possibility is that Generation Z's self-awareness in Indonesia is quite low. This can be noticed in the PSU and stress control, although the PSU and stress levels are moderate, but the control data such as the intensity of smartphone use and the intensity of stress in the last month that are obtained tend to be high. So that it can be concluded, the cause of stress for failing to be a moderator for the two relationships is because stress has a relatively low relationship with FoMO and PSU and awareness or self-awareness in Generation $\mathrm{Z}$ also tends to be low.
In the course of this research, there were several shortcomings or limitations experienced. First, the number of participants was found only as many as 300 people. Second, this study only focuses on the relationship between variables and the age of the participants but does not involve several other things such as gender, so that a picture of gender and gender is not found in this study. It is hoped that further research can involve gender to see any differences based on gender. It has been previously explained that stress has a lower relationship than depression on PSU [28], the authors suggest that further research can replace stress with depression as a moderator. If you want to keep researching with the same variables, the authors suggest changing the subject to another generation such as the Millennial generation. Because McMahon and Pospisil in 2005 [48] explained that the Millennial generation is very fond of looking for social interaction through social media, considering that there is no smartphone communication tool in that year, it does not rule out the level of FoMO and PSU is also high. What supports the previous suggestion is that the Millennial generation's stress level in the latest APA [7] survey is the highest when compared to other generations.

\section{CONCLUSIONS}

Through the results of data received and analyzed, it was found that fear of missing out (FoMO) has a positive and significant relationship with problematic smartphone use (PSU) in Generation Z, however in this study it was also found that stress was unable to become a moderator variable towards the relationship. This shows that when Generation $\mathrm{Z}$ experiences the FoMO phenomenon, it is possible if they experience the PSU phenomenon. However, when individuals in this generation experience stress, they cannot show their role in these two variables. 


\section{ACKNOWLEDGMENT}

This work was supported by Tarumanagara University, Jakarta, Indonesia.

\section{REFERENCES}

[1] J. Curran, N. Fenton, and D. Freedman, Misunderstanding the internet, 2nd ed. Routledge/Taylor\& Francis Group, 2016.

[2] S. O'Dea, "Smartphone users worldwide 2016-2021," Statista, 2020. [Online]. Available: https://www.statista. com/statistics/330695/number-of-smartphone-usersworldwide/. [Accessed: 01-Nov-2020]

[3] M. Anderson and J. Jiang, "Teens, Social Media \& Technology 2018," 2018 [Online]. Available: http://assets.pewresearch.org/wpcontent/uploads/sites/14/2 018/05/31102617/PI_2018.05.31_TeensTech_FINAL.pdf

[4] App Annie, "State of Mobile," 2020 [Online]. Available: https://gertkoot.files.wordpress.com/2020/01/ 2001_state_of_mobile_2020_main_en-1.pdf

[5] KumparanTECH, "Orang indonesia pakai smartphone selama 4 jam per hari," Kumparan, 2020. [Online]. Available: https://kumparan.com/kumparantech/orangindonesia-pakai-smartphone-selama-4-jam-per-hari1seYR8T9ATq. [Accessed: 16-Jan-2020]

[6] Asosiasi Penyelenggara Jasa Internet Indonesia, "Penetrasi \& profil perilaku pengguna internet Indonesia," 2017 [Online]. Available: https://apjii.or.id/survei2018s/ download/TK5oJYBSyd8iqHA2eCh4FsGELm3ubj

[7] American Psychological Association, "Stress in America $^{\mathrm{TM}}$ Generation Z," 2018 [Online]. Available: https://www.apa.org/news/press/releases/stress/2018

[8] H. M. Van Praag, "Can stress cause depression?," Prog. Neuro-Psychopharmacology Biol. Psychiatry, vol. 28, no. 5, pp. 891-907, 2004, doi: 10.1016/j.pnpbp.2004.05.031.

[9] L. A. King, The science of psychology: An appreciative view, 2nd ed. New York, NY, 2011.

[10] D. Kardefelt-Winther, “A conceptual and methodological critique of internet addiction research: Towards a model of compensatory internet use," Comput. Human Behav., vol. 31, no. 1, pp. 351-354, 2014, doi: 10.1016/j.chb.2013.10.059. [Online]. Available: http://dx. doi.org/10.1016/j.chb.2013.10.059

[11] J. Billieux, P. Maurage, O. Lopez-Fernandez, D. J. Kuss, and M. D. Griffiths, "Can Disordered Mobile Phone Use Be Considered a Behavioral Addiction? An Update on Current Evidence and a Comprehensive Model for Future
Research," Curr. Addict. Reports, vol. 2, no. 2, pp. 156162, 2015, doi: 10.1007/s40429-015-0054-y.

[12] C. Lee and S. J. Lee, "Prevalence and predictors of smartphone addiction proneness among Korean adolescents," Child. Youth Serv. Rev., vol. 77, no. January, pp. 10-17, 2017, doi: 10.1016/j.childyouth.2017.04.002. [Online]. Available: http://dx.doi.org/10.1016/j.childyouth. 2017.04.002

[13] C. C. Arthy, E. Effendy, M. M. Amin, B. Loebis, V. Camellia, and M. S. Husada, "Indonesian version of addiction rating scale of smartphone usage adapted from smartphone addiction scale-short version (SAS-SV) in junior high school," Open Access Maced. J. Med. Sci., vol. 7, no. 19, pp. 3235-3239, 2019, doi: 10.3889/oamjms. 2019.691 .

[14] A. Lepp, J. E. Barkley, and A. C. Karpinski, "The relationship between cell phone use, academic performance, anxiety, and Satisfaction with Life in college students," Comput. Human Behav., vol. 31, no. 1, pp. 343 350, 2014, doi: 10.1016/j.chb.2013.10.049. [Online]. Available: http://dx.doi.org/10.1016/j.chb.2013.10.049

[15] A. K. Przybylski, K. Murayama, C. R. Dehaan, and V. Gladwell, "Motivational, emotional, and behavioral correlates of fear of missing out," Comput. Human Behav., vol. 29, pp. 1841-1848, 2013, doi: 10.1016/j.chb.2013.02.014. [Online]. Available: http://dx. doi.org/10.1016/j.chb.2013.02.014

[16] P. R. Hetz, C. L. Dawson, and T. A. Cullen, "Social media use and the fear of missing out (FoMO) while studying abroad," J. Res. Technol. Educ., vol. 47, no. 4, pp. 259-272, 2015, doi: 10.1080/15391523.2015.1080585.

[17] D. Alt, "College students' academic motivation, media engagement and fear of missing out," Comput. Human Behav., vol. 49, pp. 111-119, 2015, doi: 10.1016/j.chb.2015.02.057. [Online]. Available: http://dx. doi.org/10.1016/j.chb.2015.02.057

[18] J. Rifkin, C. Cindy, and B. Kahn, "Fomo: How the fear of missing out leads to missing out," Assoc. Consum. Res., vol. 43, p. 246, 2015 [Online]. Available: http://www. acrwebsite.org/volumes/1019794/volumes/v43/NA-43

[19] J. Fox and J. J. Moreland, "The dark side of social networking sites: An exploration of the relational and psychological stressors associated with Facebook use and affordances," Comput. Human Behav., vol. 45, pp. 168 176, 2015, doi: 10.1016/j.chb.2014.11.083. [Online]. Available: http://dx.doi.org/10.1016/j.chb.2014.11.083

[20] K. Moore and G. Craciun, "Fear of missing out and personality as predictors of social networking sites usage: The instagram case," Psychol. Rep., pp. 1-27, 2020, doi: 10.1177/0033294120936184. 
[21] G. Lo Coco, L. Salerno, V. Franchina, A. La Tona, M. Di Blasi, and C. Giordano, "Examining bi-directionality between Fear of Missing Out and problematic smartphone use. A two-wave panel study among adolescents," Addict. Behav., vol. 106, pp. 1-6, 2020, doi: 10.1016/j. addbeh.2020.106360. [Online]. Available: https://doi.org/ 10.1016/j.addbeh.2020.106360

[22] C. A. Wolniewicz, M. F. Tiamiyu, J. W. Weeks, and J. D. Elhai, "Problematic smartphone use and relations with negative affect, fear of missing out, and fear of negative and positive evaluation," Psychiatry Res., vol. 262, no. September, pp. 618-623, 2018, doi: 10.1016/ j.psychres.2017.09.058. [Online]. Available: http://dx.doi. org/10.1016/j.psychres.2017.09.058

[23] J. D. Elhai, E. F. Gallinari, D. Rozgonjuk, and H. Yang, "Depression, anxiety and fear of missing out as correlates of social, non-social and problematic smartphone use," Addict. Behav., vol. 105, p. 106335, 2020, doi: 10.1016/j.addbeh.2020.106335. [Online]. Available: https: //doi.org/10.1016/j.addbeh.2020.106335

[24] R. Servidio, "Self-control and problematic smartphone use among Italian University students: The mediating role of the fear of missing out and of smartphone use patterns," Curr. Psychol., 2019, doi: 10.1007/s12144-019-00373-z.

[25] J. D. Elhai, H. Yang, J. Fang, X. Bai, and B. J. Hall, "Depression and anxiety symptoms are related to problematic smartphone use severity in Chinese young adults: Fear of missing out as a mediator," Addict. Behav., 2020, doi: 10.1016/j.addbeh.2019.04.020. [Online]. Available: https://doi.org/10.1016/j.addbeh.2019.04.020

[26] J. D. Elhai, J. C. Levine, R. D. Dvorak, and B. J. Hall, "Fear of missing out, need for touch, anxiety and depression are related to problematic smartphone use," Comput. Human Behav., vol. 63, pp. 509-516, 2016, doi: 10.1016/j.chb.2016.05.079. [Online]. Available: http:// dx.doi.org/10.1016/j.chb.2016.05.079

[27] J. D. Elhai, H. Yang, D. McKay, and G. J. G. Asmundson, "COVID-19 anxiety symptoms associated with problematic smartphone use severity in Chinese adults," J. Affect. Disord., vol. 274, no. April, pp. 576-582, 2020, doi: 10.1016/j.jad.2020.05.080. [Online]. Available: https://doi.org/10.1016/j.jad.2020.05.080

[28] J. D. Elhai, R. D. Dvorak, J. C. Levine, and B. J. Hall, "Problematic smartphone use: A conceptual overview and systematic review of relations with anxiety and depression psychopathology," J. Affect. Disord., vol. 207, pp. 251-259, 2017, doi: 10.1016/j.jad.2016.08.030. [Online]. Available: http://dx.doi.org/10.1016/j.jad.2016.08.030

[29] J. H. Kim, M. Seo, and P. David, "Alleviating depression only to become problematic mobile phone users: Can face-to-face communication be the antidote?," Comput. Human Behav., vol. 51, no. PA, pp. 440-447, 2015, doi: 10.1016/j.chb.2015.05.030. [Online]. Available: http:// dx.doi.org/10.1016/j.chb.2015.05.030

[30] J. L. Wang, H. Z. Wang, J. Gaskin, and L. H. Wang, "The role of stress and motivation in problematic smartphone use among college students," Comput. Human Behav., vol. 53, pp. 181-188, 2015, doi: 10.1016/j.chb.2015.07.005. [Online]. Available: http://dx. doi.org/10.1016/j.chb.2015.07.005

[31] E. Wegmann, U. Oberst, B. Stodt, and M. Brand, "Online-specific fear of missing out and internet-use expectancies contribute to symptoms of Internetcommunication disorder," Addict. Behav. Reports, vol. 5, pp. 33-42, 2017, doi: 10.1016/j.abrep.2017.04.001. [Online]. Available: http://dx.doi.org/10.1016/j.abrep. 2017.04.001

[32] L. Dossey, "FOMO, digital dementia, and our dangerous experiment," Explor. J. Sci. Heal., vol. 10, no. 2, pp. 69-73, 2014, doi: 10.1016/j.explore.2013.12.008. [Online]. Available: http://dx.doi.org/10.1016/j.explore. 2013.12.008

[33] Z. G. Baker, H. Krieger, and A. S. LeRoy, "Fear of missing out: Relationships with depression, mindfulness, and physical symptoms.," Transl. Issues Psychol. Sci., vol. 2, no. 3, pp. 275-282, 2016, doi: 10.1037/tps0000075.

[34] S. Thomée, "Mobile phone use and mental health. A review of the research that takes a psychological perspective on exposure," Int. J. Environ. Res. Public Health, vol. 15, no. 12, 2018, doi: 10.3390/ijerph15122692.

[35] J. D. S. Gutiérrez, F. R. de Fonseca, and G. Rubio, "Cell-phone addiction: A review," Front. Psychiatry, vol. 7, no. OCT, 2016, doi: 10.3389/fpsyt.2016.00175.

[36] J. S. Nevid, S. A. Rathus, and B. Greene, Abnormal psychology: In a changing world, 9th ed., no. 9. New Jersey, United States of America: Pearson Education, Inc, 2013.

[37] R. S. Lazarus, "Theory-Based Stress Measurement Richard," Psychol. Inq., vol. 1, no. 1, pp. 3-13, 1990, doi: 10.1207/s15327965pli0101.

[38] S. Hintz, P. A. Frazier, and L. Meredith, "Evaluating an online stress management intervention for college students," J. Couns. Psychol., vol. 62, no. 2, pp. 137-147, 2015, doi: 10.1037/cou0000014.

[39] S. Young, "Social media being used by growing number of children under 11 despite age limits," Independent, 2019 [Online]. Available: https://www. independent.co.uk/life-style/children-social-media-useage-limit-facebook-instagram-profiles-a8756096.html. [Accessed: 31-Jan-2019]

[40] M. Dimock, "Defining generations: Where Millennials end and Generation Z begins," 2019 [Online]. Available: 
https://www.pewresearch.org/fact-tank/2019/01/17/wheremillennials-end-and-generation-z-begins/

[41] C. Seemiller and M. Grace, Generation Z goes to college. John Wiley \& Sons, Inc., 2016 [Online]. Available: http://www.eskom.co.za/CustomerCare/TariffsAndCharge s/Documents/RSA Distribution Tariff Code Vers 6.pdf\%0Ahttp://www.nersa.org.za/

[42] A. Turner, "Generation Z: Technology and Social Interest Generation Z: Technology and Social Interest," $J$. Individ. Psychol., vol. 71, no. 2, pp. 103-113, 2015.

[43] J. Van den Bergh and M. Behrer, How Cool Brands Stay Hot: Branding to Generations $Y$ and $Z$. Kogan Page Publishers, 2016.

[44] F. Sutanto, R. Sahrani, and D. Basaria, "Fear of Missing Out (FoMO) and Psychological Well-Being of Late Adolescents Using Social Media," no. December, 2020, doi: 10.2991/assehr.k.201209.071.

[45] M. Kwon, D. J. Kim, H. Cho, and S. Yang, "The smartphone addiction scale: Development and validation of a short version for adolescents," PLoS One, vol. 8, no. 12, pp. 1-7, 2013, doi: 10.1371/journal.pone.0083558.

[46] M. T. A. F. Lim and S. Kartasasmita, "Dukungan internal atau eksternal; Self-compassion dan perceived social support sebagai prediktor stres," J. Muara Ilmu Sos. Humaniora, dan Seni, vol. 2, no. 2, p. 551, 2019, doi: 10.24912/jmishumsen.v2i2.1587.

[47] S. Cohen, To. Kamarck, and R. Mermelstein, "A Global Measure of Perceived Stress," J. Health Soc. Behav., vol. 24, no. 4, pp. 385-396, 2014.

[48] M. Mcmahon and R. Pospisil, "Laptops for a digital lifestyle: Millennial students and wireless mobile technologies," in ASCILITE 2005 - The Australasian Society for Computers in Learning in Tertiary Education, 2005, pp. 421-431. 